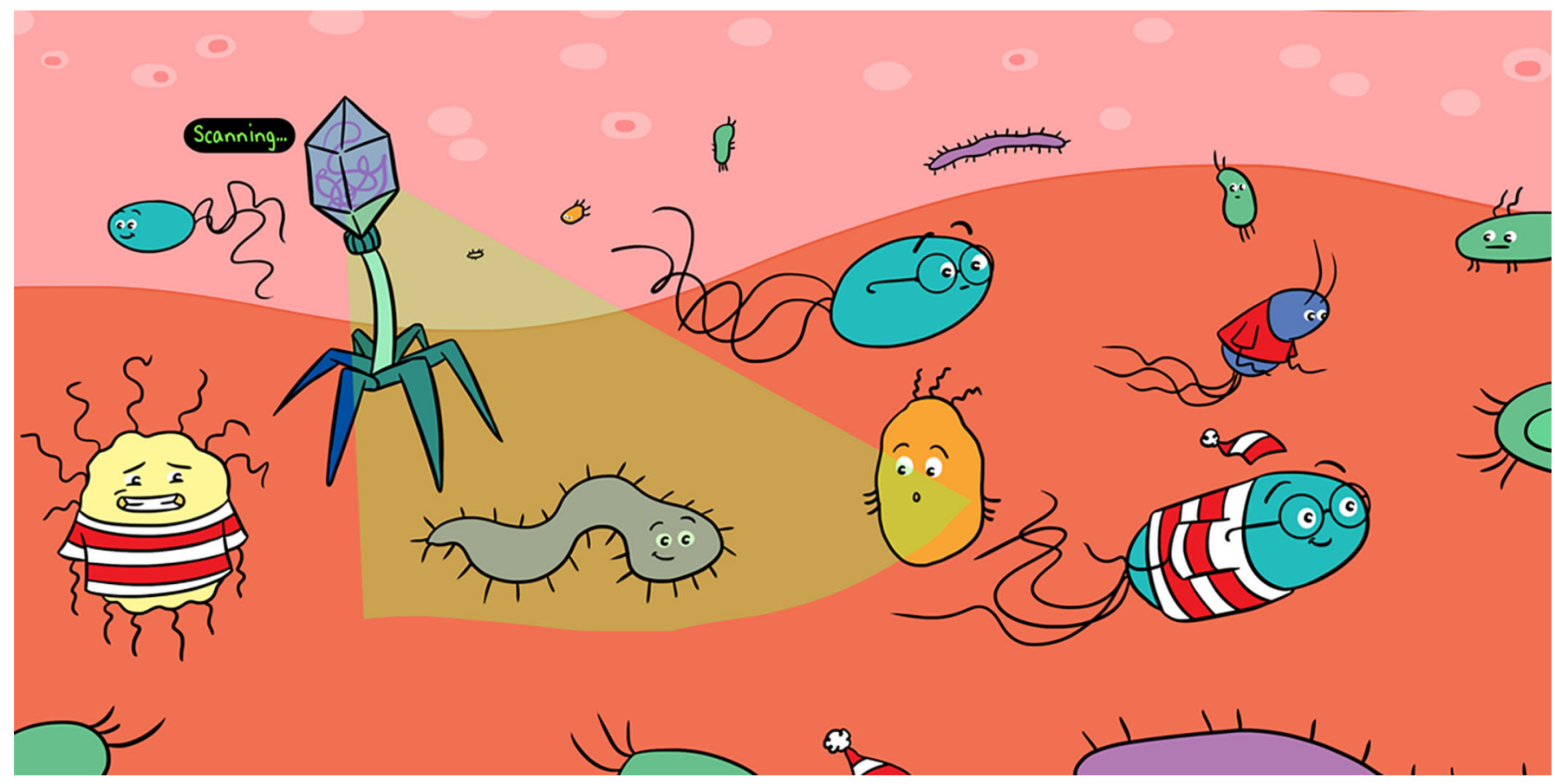

\title{
NATURAL BACTERIA KILLERS: HOW BACTERIOPHAGES FIND AND ELIMINATE THEIR HOSTS
}

\section{Floricel Gonzalez * and Birgit E. Scharf}

Scharf Laboratory, Department of Biological Sciences, Virginia Polytechnic Institute and State University, Blacksburg, VA, United States

YOUNG REVIEWERS:

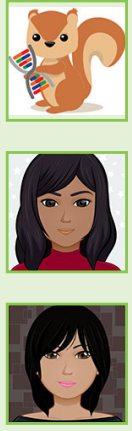

\section{ARIA}

AGE: 8

RUH-FAIDA

AGE: 12

SAMIHA

AGE: 12

\section{BACTERIA}

A one-celled microbe that can be found everywhere in nature and can either cause disease or be beneficial.

Bacteriophages, also called phages, are viruses that kill bacteria. They do not kill humans, animals, or plants. Phages only kill one or a few types of bacteria. Therefore, we can use phages that only kill disease-causing bacteria as medicines. Using phages ensures that the helpful bacteria stay alive. How do phages kill some bacteria and not others? They recognize specific parts of a bacterial cell. In this article, we describe how phages find their target bacteria even when other microbes are around.

\section{PHAGES ARE ALL AROUND US}

Earth is jam-packed with bacteria-and the viruses that infect them! These viruses are called bacteriophages, or just phages (pronounced feyj-es) for short. There are 10 times more phages than bacteria on earth [1]. Bacteriophages are fun to look at because they come in different shapes (Figure 1A). Some have tails that are flexible, rigid, or 
Figure 1

Diversity of phages and how they attack bacteria. (A) Phages have many shapes. They can have different types of tails or no tail, or simply look like a string. (B) Phages attack bacteria by recognizing and sticking to the bacterial cell. Then, the phage enters the cell, makes many phage copies, and the cell bursts open, which releases hundreds of new phages.

\section{VIRUS}

A microbe that must infect a cell

to reproduce.

\section{BACTERIOPHAGE}

$A$ virus that

infects bacteria.

\section{MICROBE}

A small organism that is typically not visible with the naked eye.

Microbes include bacteria and viruses.

\section{HOST}

A cell used by a virus to reproduce.

\section{ANTIBIOTIC-}

\section{RESISTANT}

A term used to describe bacteria that are no longer sensitive to the medicines normally used to kill them or stop their growth.
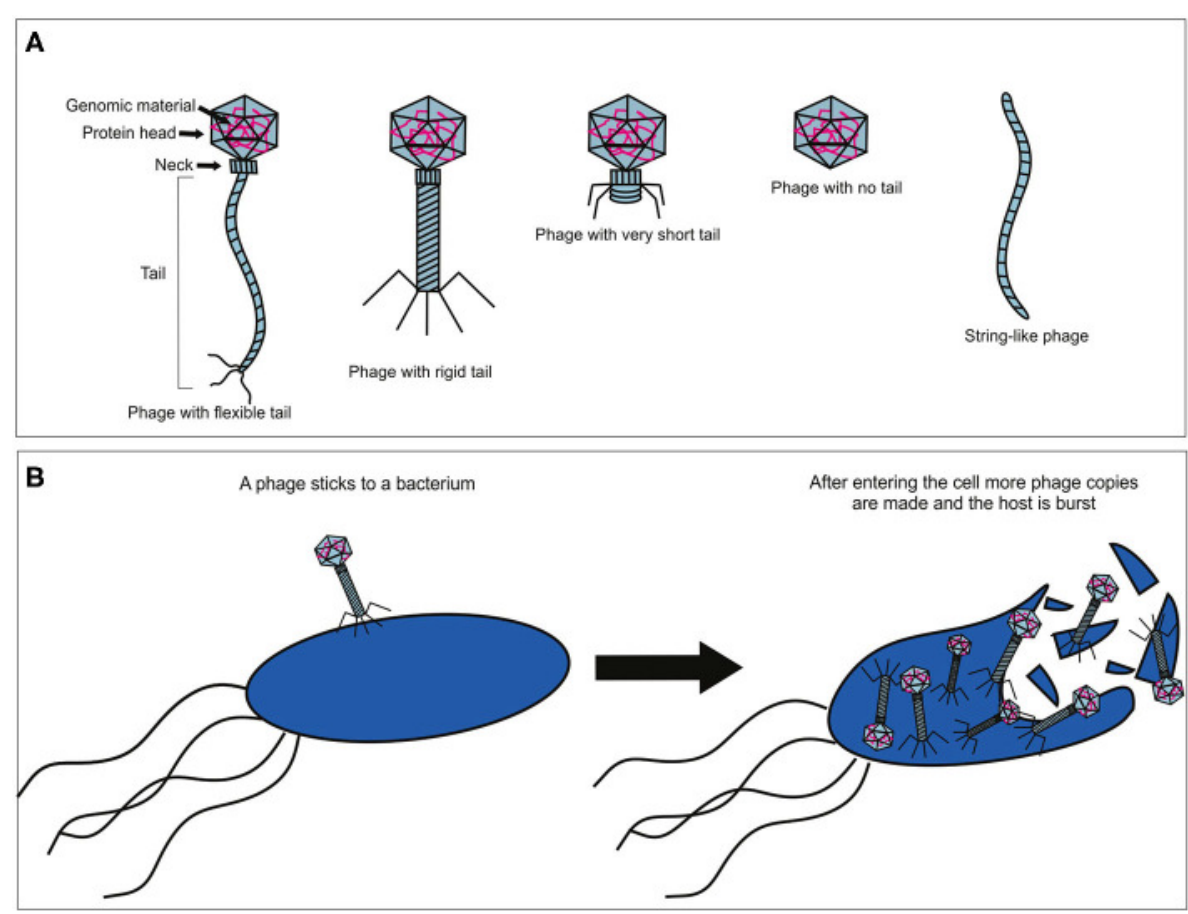

Figure 1

very short. Others look like floating heads or even like long strings. Just like other microbes, phages are made from a set of genetic instructions known as DNA or RNA. These instructions are safely housed in the phage head, which is made of protein (Figure 1A).

Phages (like all viruses) cannot reproduce by themselves nor make new phage copies. Viruses always need a cell to infect, called a host cell, to reproduce themselves. Bacteriophages take advantage of bacteria for this purpose. These microscopic pirates begin their attack by sticking to a bacterial cell. Then, the phage enters the cell and makes more copies of itself. How many copies are made? Hundreds! For every bacterial cell that is attacked, hundreds of new phages are created. These copies are freed as the bacterial cell explodes (Figure 1B) [1, 3, 4]. All of this begins with one phage. This process is happening in the soil, oceans, and even in your own body!

Humans are using these natural enemies of bacteria for the greater good. For example, phages can be used as medicines to kill disease-causing bacteria that are antibiotic-resistant, meaning that normal drug treatments used to kill them are no longer effective. In other cases, phages are applied to cooking surfaces, meat, or produce. This prevents bad bacteria that can cause fever and diarrhea, like Salmonella and Listeria monocytogenes, from getting on our food $[2,3]$. As you can see, phages are the good viruses. They help us stay healthy and protected from disease-causing bacteria. 
Figure 2

Phages find their specific hosts with a microbial version of Where is Waldo ${ }^{\circledR}$ ? Phages use receptors on the surface of bacterial cells to recognize their hosts, just like players of Where is Waldo ${ }^{\circledR}$ recognize Waldo by looking for his outfit. Can you find the Waldo bacteria?

\section{RECEPTOR}

A unique feature of the host cell that is recognized by a virus.

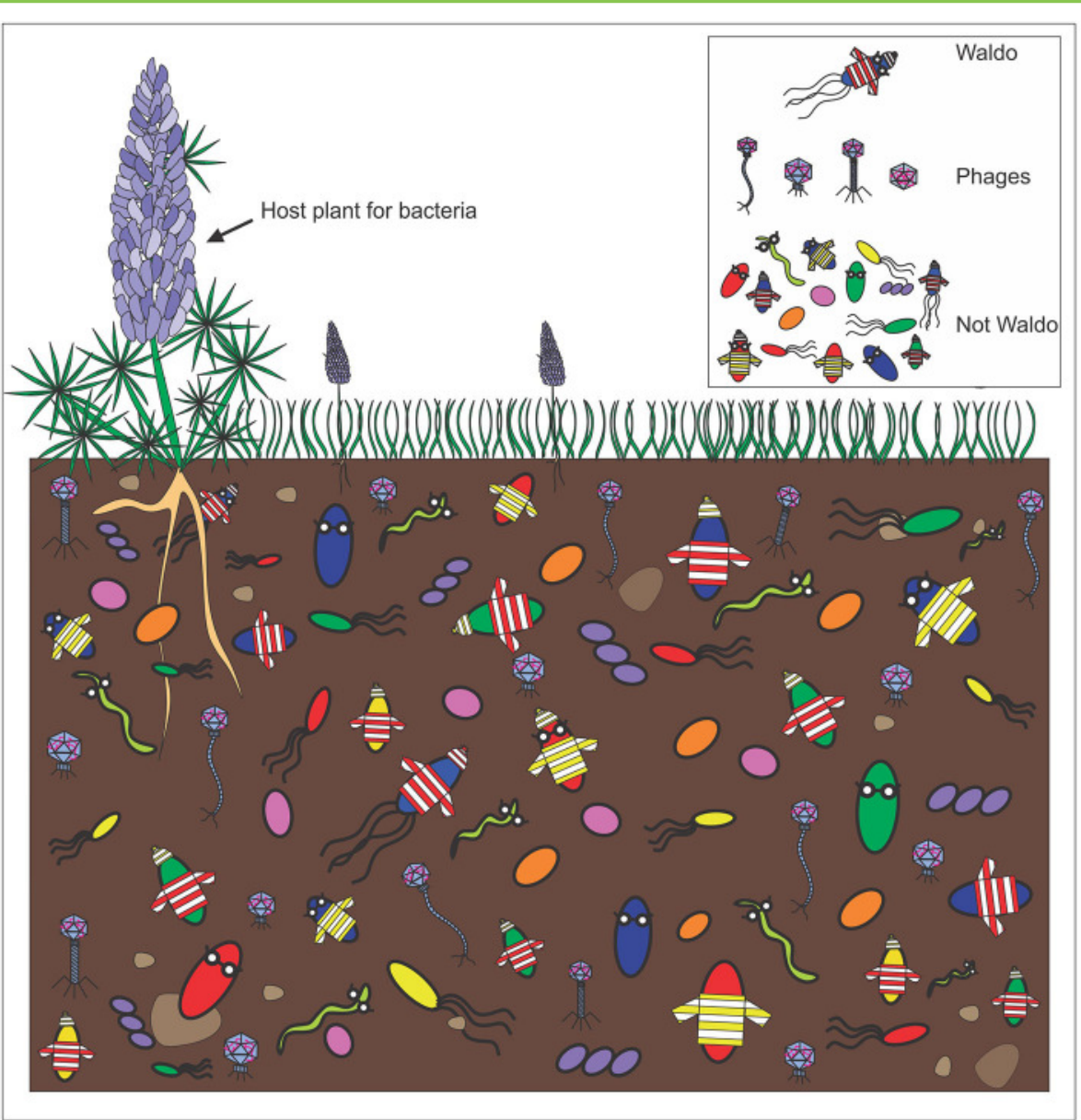

Figure 2

\section{PHAGES RECOGNIZE SOME BACTERIA AND LEAVE THE REST ALONE}

Even though there are many types of bacteria everywhere, phages only attack some of them. How do phages know which bacteria to kill? It turns out that phages are picky! Each phage is only able to use certain types of bacteria as hosts. Phages search for their hosts by sifting through all the microbes around them. This is like playing the Where is Waldo ${ }^{\circledR}$ puzzle game. To find Waldo, you search for a character with glasses, brown hair, a red-and-white striped beanie with a matching shirt, and blue jeans. There may be others in the picture who are wearing similar outfits or parts of Waldo's outfit, but only Waldo is wearing the complete, correctly colored outfit. Phages play a microbe version of this game with bacteria (Figure 2).

To find their hosts, phages look for special parts of the bacterial cell. These parts recognized by the phage are called receptors [3]. The receptors serve the same purpose that Waldo's outfit does in Where is Waldo ${ }^{\circledR}$. They make the hosts stand out from other microbes around them. Therefore, bacteria without the right receptors are safe from phage attack. The receptors are also the areas where the 
Figure 3

Functions of some bacterial structures that bacteriophages use as receptors to attach to bacterial cells. (A) Flagella are used for movement. Bacteria that move are better at reaching food than bacteria that do not move. (B) Sugar molecules on the surface of bacteria can be used as receptors.

These sugar layers protect bacteria from toxic molecules in the environment. (C) Protein pumps in the cell membrane of a bacterial cell can also be used as receptors. These pumps remove toxic molecules from inside the bacterial cell.

\section{FLAGELLA}

Long threads that are part of a bacterial cell. Flagella are used to move around in a swimming motion.

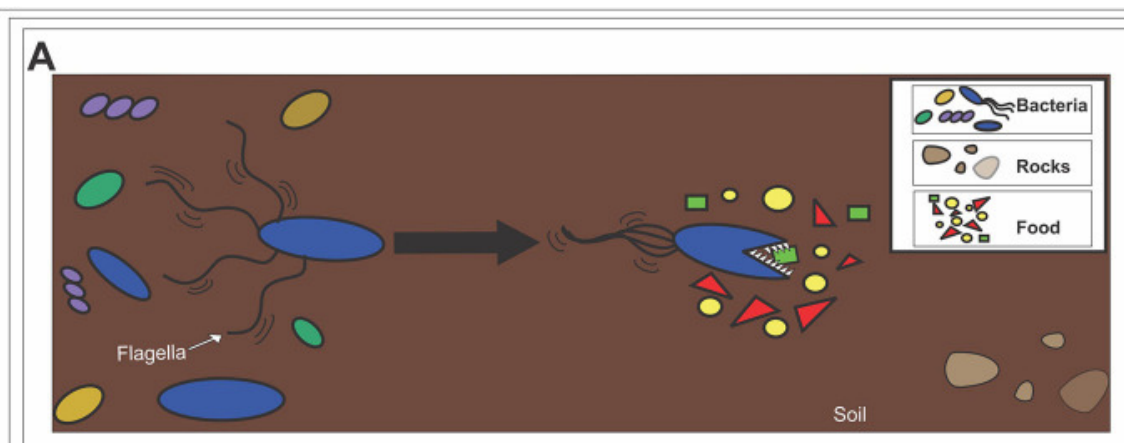

\section{B}

Bacteria encounter toxic molecules
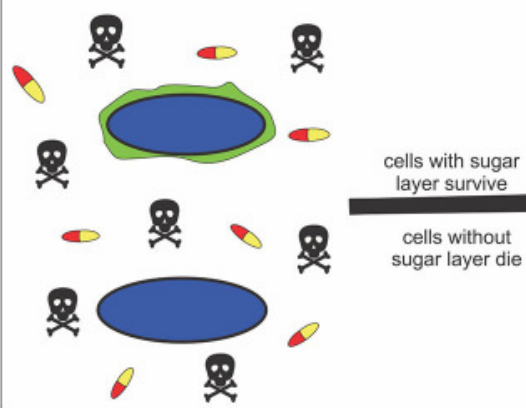

cells without
sugar layer die
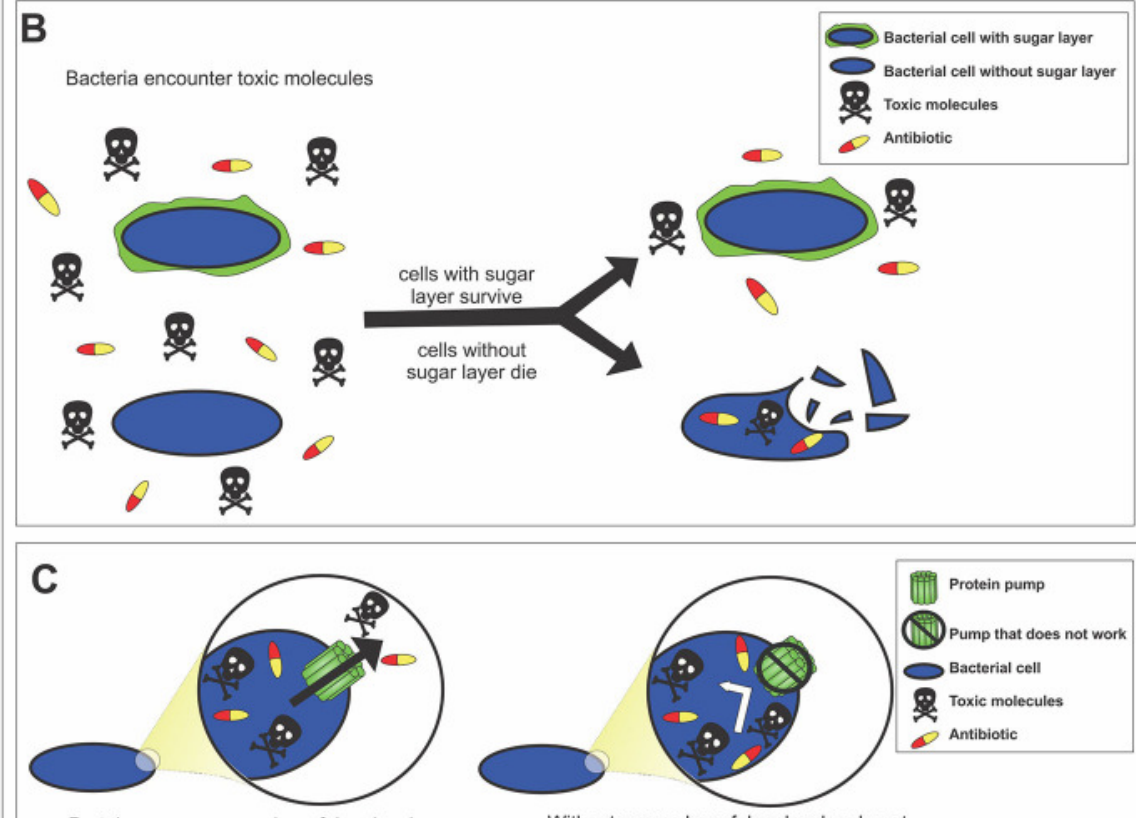

Protein pump removes harmful molecules

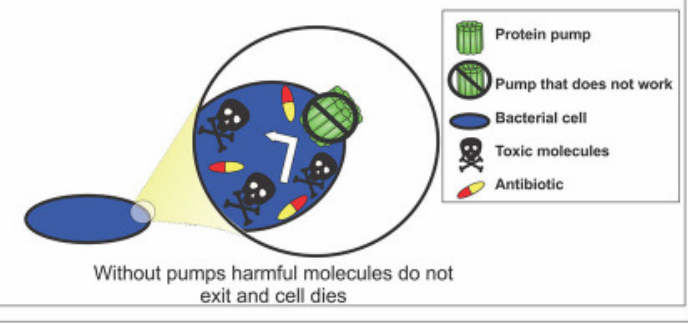

Figure 3

phage attaches, or sticks, to the bacterial cell at the beginning of the attack.

\section{RECEPTORS USED BY PHAGES ARE IMPORTANT FOR BACTERIA}

What kind of bacterial cell parts are used by phages as receptors? It depends on the phage! Some phages stick to flagella (pronounced fluh-jeh-lah), which are long, wavy threads used by bacteria to move in a swimming motion (Figure 3A). Other phages stick to sugars found on the surface of the bacterial cell that normally protects bacteria from toxic substances (Figure 3B). Protein pumps found in the bacteria's cell membrane are also used as receptors. The cell membrane is the barrier around the cell that helps it keep its shape, and the protein pumps normally get rid of things that can harm or kill the cell (Figure 3C). 
Although we will only mention these three receptors, keep in mind that there are more $[3,5]$. Not all bacteria have sugars, flagella, or protein pumps. Depending on where they live, bacteria may need other specialized parts that allow them to survive. Interestingly, the parts that make each type of bacteria unique are what phages recognize. The receptors used by phages determine which bacteria are their hosts. Phages can have either a broad or narrow host range. Phages with a broad host range can attack many different types of bacteria. Phages with a narrow host range attack only one or two types of bacteria.

Bacteria can protect themselves from phages by removing or changing the receptors on their surfaces. However, this comes at a cost to the bacterial cells. Receptors play important roles in the life functions of bacteria. The primary job of receptors is to help bacteria perform those functions, not to make phage attack possible. Removing or changing the receptors can leave the cell unable to perform certain critical functions. For example, bacteria that can move can travel to new areas where more food is present, which means they can out-compete bacteria that cannot move (Figure 3A). If bacteria change to get rid of their flagella, they would be resistant to the phage, but no longer able to move and look for food. Similarly, if the protein pumps or sugar layers are gone, then the bacterial cell is more likely to die in harsh environments (Figures 3B,C). Despite these downsides, some bacteria still change or remove receptors to avoid phage attack.

Surprisingly, phages can overcome the defenses of bacteria. Phages can learn to recognize a different cell part or the altered receptor. How does this happen? Mostly by chance. When new phages are made, some are different from the original phage that first infected the bacterial cell. This is caused by mutations, small changes that naturally occur in DNA or RNA. Mutations happen in bacterial, animal, and human cells. Mutations sometimes give cells advantages over other cells. In fact, humans can walk on two legs thanks to mutations. In phages, these mutations can result in the ability to infect bacteria that would otherwise be phage resistant. This cycle of bacteria becoming phage resistant and phages overcoming that resistance repeats itself over and over. In this way, bacteria and phages are constantly in competition with each other $[4,5]$.

\section{WHY SHOULD YOU CARE ABOUT PHAGES?}

Even though viruses are often thought of as bad, phages are helpful viruses that we want to have around. These natural killers of bacteria are extremely good at what they do! So, we can use them to kill the bad bacteria that cause diseases and hard-to-treat infections. In fact, phages have already made news headlines for saving lives. Bacteriophages have cured humans from bacterial infections of the heart, brain, and urinary tract. These infections are caused by problematic bacteria, such as Pseudomonas aeruginosa or 
Acetinobacter baumannii [5], which quickly become resistant to many antibiotics. Some problematic bacteria also form sticky layers called biofilms that are hard to break apart. For these reasons, antibiotics are not always an effective option for treatment. Therefore, phages may be the only way to get rid of these dangerous infections.

By using phages that only kill these troublemakers, we can make sure that the good bacteria in our bodies survive. We need to study phages in more detail, just like we study other medicines we use. These studies will help us choose the best phages to use in treatments. In the meantime, you can help spread the word about these incredible viruses. Next time you hear someone talk about viruses, be sure to tell them what you know about phages-the good viruses that can help treat infections!

\section{ACKNOWLEDGMENTS}

We thank Connor Caswell and Nathalia Barajas Gonzalez for providing us with invaluable feedback on an early draft of this manuscript.

\section{REFERENCES}

1. Jurczak-Kurek, A., Gasior, T., Nejman-Faleńczyk, B., Bloch, S., Dydecka, A., Topka, G., et al. 2016. Biodiversity of bacteriophages: morphological and biological properties of a large group of phages isolated from urban sewage. Sci. Rep. 6:34338. doi: 10.1038/srep34338

2. Kahn, L. H., Bergeron, G., Bourassa, M. W., De Vegt, B., Gill, J., Gomes, F., et al. 2019. From farm management to bacteriophage therapy: strategies to reduce antibiotic use in animal agriculture. Ann. N. Y. Acad. Sci. 1441:31. doi: $10.1111 /$ nyas.14034

3. Stone, E., Campbell, K., Grant, I., and McAuliffe, O. 2019. Understanding and exploiting phage-host interactions. Viruses 11:567. doi: 10.3390/v11060567

4. Koskella, B., and Brockhurst, M. A. 2014. Bacteria-phage coevolution as a driver of ecological and evolutionary processes in microbial communities. FEMS Microbiol. Rev. 38:916-31. doi: 10.1111/1574-6976.12072

5. Kortright, K. E., Chan, B. K., Koff, J. L., and Turner, P. E. 2019. Phage therapy: a renewed approach to combat antibiotic-resistant bacteria. Cell Host Microbe 25:219-32. doi: 10.1016/j.chom.2019.01.014

SUBMITTED: 20 June 2020; ACCEPTED: 08 February 2021; PUBLISHED ONLINE: 03 March 2021.

EDITED BY: Michel Goldman, Institute for Interdisciplinary Innovation in healthcare (I3h), Belgium

CITATION: Gonzalez F and Scharf BE (2021) Natural Bacteria Killers: How Bacteriophages Find and Eliminate Their Hosts. Front. Young Minds 9:574664. doi: 10.3389/frym.2021.574664 

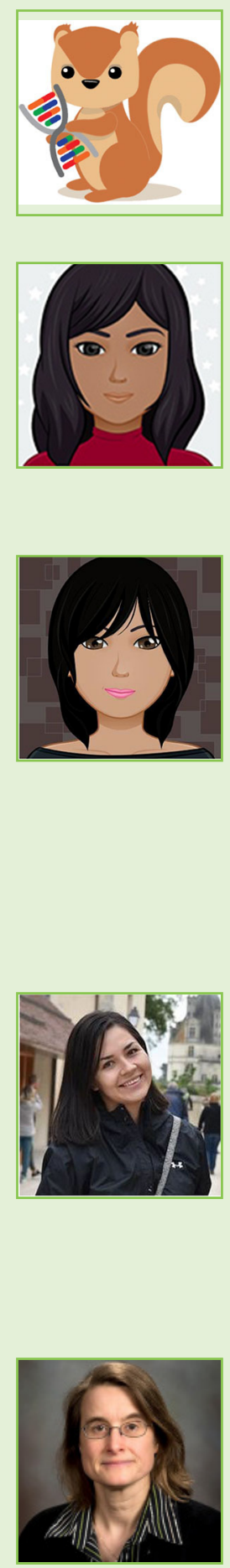

CONFLICT OF INTEREST: The authors declare that the research was conducted in the absence of any commercial or financial relationships that could be construed as a potential conflict of interest.

COPYRIGHT @ 2021 Gonzalez and Scharf. This is an open-access article distributed under the terms of the Creative Commons Attribution License (CC BY). The use, distribution or reproduction in other forums is permitted, provided the original author(s) and the copyright owner(s) are credited and that the original publication in this journal is cited, in accordance with accepted academic practice. No use, distribution or reproduction is permitted which does not comply with these terms.

\section{YOUNG REVIEWERS}

\section{ARIA, AGE: 8}

Aria loves playing with her two guinea pigs and feeding the birds and squirrels in her backyard. She gave each squirrel a unique name and lots of peanuts. Aria is always curious about science and she has a lot of questions about nature, animals, and the universe. She also likes singing and drawing in her spare time.

\section{RUH-FAIDA, AGE: 12}

My name is Ruh-Faida and I am 12 years old. At school, I am in year 7. I was born in Bangladesh, but my family and I moved to Australia when I just 3 months of age. I have a younger sister who was born here, and she is 8 years old. We have lived in four different cities after coming to Australia, but we occasionally do go back to Bangladesh to visit the rest of our family. I love nature and animals.

\section{SAMIHA, AGE: 12}

My name is Samiha and I am 12 years old. I am grade- 7 student. I have many hobbies and passions. First of all, my favorite subject is definitely math. I specifically love geometry and anything to do with angles. I like to read, but, only books that I find interesting (books about mysteries, horror, and secret organizations). I have always wanted to visit France and I really like to cook and bake, mostly because they both involve food which I love!

\section{AUTHORS}

\section{FLORICEL GONZALEZ}

Floricel is a microbiologist at Virginia Tech. Her love for viruses began in college where she learned about the crafty ways viruses infect their hosts. When she was taught about bacteriophages, the viruses of bacteria, she knew she had to work on them. Now, she is a Ph.D. candidate studying how phages recognize and attack bacteria that move. She is also interested in the discovery of phage proteins that can kill bacteria. The goal of her work is to use phages, or parts of phages, to get rid of disease-causing bacteria in agriculture. *floric1@avt.edu

\section{BIRGIT E. SCHARF}

Dr. Birgit Scharf is a molecular microbiologist at Virginia Tech. She is interested in flagellar-driven bacterial movement and how bacteriophages use this trait for 
infection. Dr. Scharf has studied disease-causing and beneficial microbes at several research institutions in Germany and the U.S.A. Her current research group primarily investigates both how plant-growth-promoting bacteria find host plants, and how phages that use flagella as receptors infect various bacterial species. This research may eventually help us to increase crop yields and establish alternative methods to treat and eliminate pathogenic bacteria from plants and meat products. 